\title{
Too Good To Be True: Influencing Credibility Perceptions with Signaling Reference Explicitness and Assurance Depth
}

\author{
Carolin Baier $^{1}$ (D) $\cdot$ Max Göttsche ${ }^{1}$ (D) $\cdot$ Andreas Hellmann ${ }^{2}$ (D) $\cdot$ Frank Schiemann $^{3}$ (D)
}

Received: 11 May 2020 / Accepted: 22 December 2020 / Published online: 1 February 2021

(c) The Author(s) 2021

\begin{abstract}
We investigate how the selection of assurance topics and the format of their communication influence the credibility perception of sustainability report readers. This is important because misleading communication may discredit ethical sustainability assurance practices. Based on signaling theory and using an experimental approach, we are the first to examine false credibility signals in the context of sustainability assurance. We find that two variables related to sustainability assurance, reference explicitness and assurance depth, jointly influence the assurance signal and the perceived credibility of a sustainability report. Our findings indicate that readers are not at risk of false signaling but can make incorrect interpretations of the assurance signal and might respond negatively to well-intentioned signals. The main implications of our findings are that firms should refrain from increasing reference explicitness and should select only the most material topics. Taken together, our results provide new insights on the unethical practice of false signaling and provide an example of an incorrect signal interpretation by readers.
\end{abstract}

Keywords Sustainability assurance $\cdot$ Perceived credibility $\cdot$ False signaling

\section{Introduction}

Although sustainability assurance is often voluntary, ${ }^{1}$ the number of companies obtaining third-party assurance for their sustainability reports has increased (KPMG 2017). However, considerable differences exist in the way assurance

Carolin Baier

carolin.baier@ku.de

Max Göttsche

max.goettsche@ku.de

Andreas Hellmann

andreas.hellmann@mq.edu.au

Frank Schiemann

frank.schiemann@uni-hamburg.de

1 Ingolstadt School of Management, Catholic University of Eichstätt-Ingolstadt, Auf der Schanz 49, 85049 Ingolstadt, Germany

2 Department of Accounting and Corporate Governance, Macquarie Business School, Macquarie University, Sydney, NSW 2109, Australia

3 Faculty of Business, Economics and Social Sciences, University of Hamburg, Rentzelstraße 7, 20146 Hamburg, Germany services are conducted, for example, depending on the type of provider (accountant vs. consultant; O'Dwyer and Owen 2005), and the specific topics being assured. This means that sustainability assurance offers considerable flexibility for firms, which leads to questions of unethical interferences by management regarding the choice of a limited set of sustainability topics to be assured and how to clearly communicate this choice.

The most widely used sustainability assurance standards (International Standard on Assurance Engagements [ISAE] 3000 and the AccountAbility 1000 Assurance Standard

\footnotetext{
1 The term "sustainability assurance" refers to "third party sustainability assurance" and will be used throughout the remainder of the paper. Typically, sustainability assurance is not mandated. However, recent developments towards mandated sustainability disclosures also see an increase in auditor involvement. For example, the non-financial reporting directive of the EU (2014/95/EU) contains requirements for auditors' involvement. While this requirement is restricted to ensuring the "presence of statement" (i.e., auditors check whether the required non-financial statement has been provided), some member states require additional checks (e.g., Denmark, Italy; GRI et al. 2017, p. 9).
} 
[AA1000AS] $)^{2}$ recommend that sustainability assurance follows the principle of materiality. ${ }^{3}$ A sustainability topic is material if (misstated) information about this topic has the potential to influence the decisions of intended users, such as investors and other stakeholders (Canning et al. 2019, p. 6). However, firms are not obliged to request assurance for the most material topics. Furthermore, the principle of materiality does not offer strict implementation guidance (Reimsbach et al. 2020).

In practice, firm and assurer jointly determine the intensity and scope of the performed assurance process, which influences the likelihood of discovering problematic issues in a sustainability report (Hummel et al. 2019, p. 736). Differences in assurance depth can be manifest in the selected topics of a sustainability report, for example, whether a firm chooses more or fewer material topics to be assured. In our experiment, we focus on this particular aspect of assurance depth, while leaving other aspects of assurance (e.g., assurance methods, level, recommendations, and coverage) constant (Hummel et al. 2019, pp. 743-744). We thus define assurance depth by the choice of assuring more or fewer material sustainability topics.

In this context, Cooper and Owen (2014, p. 78) criticized that management can strategically influence the assurance process through their choice of assurance depth. This poses questions of unethical interferences by management regarding how to clearly communicate which limited set of sustainability topics was assured. We investigate this behavior as an example of managerial capture ${ }^{4}$ in sustainability assurance engagements (Hummel et al. 2019; Owen et al. 2000; Smith et al. 2011).

\footnotetext{
2 The most widely used assurance standards, the International Standard on Assurance Engagements (ISAE) 3000 and the AccountAbility 1000 Assurance Standard (AA1000AS), differentiate between two levels of assurance. A reasonable (high) level of assurance requires more intensive assurance procedures to reduce the assurance engagement risk to an acceptably low level (Hummel et al. 2019, p. 744). For a limited (moderate) level, "the assurance risk is acceptable but greater than the risk expressed by a reasonable level" (Martínez-Ferrero and García-Sánchez 2018, p. 972).

3 While ISAE 3000 is transferring materiality from financial audits to sustainability assurance, the Global Reporting Initiative (GRI) Standards and the AA1000AS adopt a stakeholder-orientated interpretation of materiality (Fonseca 2010, p. 359). Materiality therefore considers "the effect each topic has on an organisation and its stakeholders" (AA 2018, p. 20).

${ }^{4}$ Managerial capture is an issue frequently discussed in sustainability assurance literature (Hummel et al. 2019; Owen et al. 2000; Smith et al. 2011). To meet their own interests (e.g., maximizing shareholder value; O'Dwyer 2003), managers take control of the assurance process and primarily provide information to strengthen the corporate image rather than supporting the principles of transparency and accountability (Owen et al. 2000, p. 85).
}

Selecting assured topics is not per se an unethical interference. However, if its application is misused, for example, by an intentionally unclear communication or obfuscated scope of assurance, it may contradict ethical assurance practices and no longer foster the credibility of sustainability reporting. We use the term reference explicitness to capture whether firms choose to indicate the assured topics in a more or less explicit form, meaning whether the choice of the assured topics is indicated less clearly via verbal information cues in the assurance report or more clearly via visual information cues throughout the sustainability report. We thus define reference explicitness by the communication choice of assurance, using visual or verbal information cues.

Note that no uniform standard exists for clearly marking and referencing which topics actually have been subject to assurance. Therefore, managements' choices of reference explicitness can make it harder or easier for the reader to correctly interpret the quality signal of sustainability assurance. Specifically, we address the following research question: "How do two strategic choices by management (reference explicitness and assurance depth) influence sustainability report readers' credibility perceptions?".

Adopting signaling theory (e.g., Jensen and Meckling 1976; Spence 1973), which is receiving increasing attention in the scholarly discourse (see Hahn and Reimsbach 2020), we examine the receiver's perspective of sustainability assurance. We critically assess sustainability assurance and investigate whether it truly signals credible information or, on the contrary, provides room for the unethical behavior of false signaling (Connelly et al. 2011, p. 45). This is important because readers rely on sustainability assurance when evaluating the information in sustainability reports (Hodge et al. 2009). The main purpose of sustainability assurance is to contribute to completeness and transparency of sustainability information and thereby increase its credibility (O'Dwyer 2011). If sustainability assurance is only disseminating the information that enhances the corporate image, rather than a true and complete picture (Owen et al. 2000 , p. 85), it might only serve symbolic purposes (Ball et al. 2000; Gray 2000). If this is the case, its primary goal is to include elements that falsely signal credibility to the reader of the sustainability report (Shen et al. 2017, p. 6), while keeping efforts and costs for the report low (Hummel et al. 2019, p. 733).

We investigate credibility perceptions for specific strategic choices of voluntary sustainability assurance, since credibility is a central aspect in the sustainability assurance literature. Gürtürk and Hahn (2016, p. 39) observed substantial differences in the choices of sustainability assurance concerning the assured content and the communication of assurance processes in the assurance report. However, it remains unclear how readers perceive differences in the choice of assured topics and the communication of this selection. 
We connect to existing literature that focuses on the quality of the assurance process in terms of assurance process depth (Hummel et al. 2019) and analyze for which communication choices we observe a distortion of sustainability report readers' perceptions (Neu 1991; Neu et al. 1998). Thereby we use an experimental $2 \times 2+1$ between-subjects design and focus on reference explicitness and assurance depth as two strategic choices by management when assigning sustainability assurance.

Our results show that for sustainability assurance with low reference explicitness, increasing the assurance depth leads to higher perceived credibility values. Interestingly, high reference explicitness leads to a reverse effect in which an increase in assurance depth causes a drop in perceived credibility. This indicates an underlying interaction effect that we interpret through the theoretical lens of signal interpretation. High reference explicitness is misinterpreted by the readers of sustainability reports as a false signal. This helps to explain the reason why only a low portion of companies choose to explicitly indicate the assured sustainability topics via visual cues (Gürtürk and Hahn 2016).

We contribute to the literature on sustainability assurance and ethical assurance practices in several ways. First, we extend prior research on sustainability assurance (e.g., Fuhrmann et al. 2017; Hodge et al. 2009; Manetti and Becatti 2009; Maroun 2020; Perego and Kolk 2012) by specifically investigating the practice of assuring only selected topics of a sustainability report. Second, extant literature comprises few studies that explicitly consider the communication of assurance (Gürtürk and Hahn 2016; Mock, Rao and Srivastava 2013; Mock, Stohm and Swartz 2007). To the best of our knowledge, this is the first study to examine different degrees of reference explicitness in the context of sustainability assurance. Sustainability assurance needs to be presented in a transparent and unambiguous form to reduce the risk of a misinterpretation of assurance by potential investors, audit providers, and companies. Third, our experimental design enables us to demonstrate that reference explicitness and assurance depth interact with each other. We reflect the results for these strategic management choices against the unethical practice of false signaling. We add to the literature on managerial capture (Hummel et al. 2019; Owen et al. 2000; Smith et al. 2011) by experimentally examining potential distortions of readers' credibility perceptions for variations of reference explicitness and assurance depth. Fourth, we contribute to studies investigating signaling theory in the context of sustainability assurance (e.g., Cheng et al. 2015; Clarkson et al. 2019; Hummel et al. 2019; Zerbini 2017).

\section{Related Literature, Theory, and Hypothesis Development}

\section{Related Literature}

Prior research typically differentiates between firms with and without sustainability assurance (Cheng et al. 2015; Coram et al. 2009; Pflugrath et al. 2011; Reimsbach et al. 2018). Some studies have focused on general assurance characteristics (e.g., type of assurance provider, assurance standard applied) or firm characteristics (e.g., industry, country level, sustainability performance; Casey and Grenier 2015; Cho et al. 2014; Kolk and Perego 2010; Simnett et al. 2009). Other research focuses on capital market consequences of sustainability assurance (Fuhrmann et al. 2017). Previous qualitative research has investigated the content of assurance reports (Ball et al. 2000; Gürtürk and Hahn 2016; Manetti and Becatti 2009; Mock et al. 2007; Perego 2009; Perego and Kolk 2012) and the process of assurance engagements (Canning et al. 2019; O’Dwyer 2011).

However, only a few studies have focused on strategic aspects in assigning sustainability assurance (Callery and Perkins 2020, pp. 25-26). As sustainability assurance is often voluntary, the firm and the assurer jointly negotiate the terms of assurance. Previous studies have criticized the degree of independence of assurers and, therefore, have also questioned audit quality (Fonseca 2010, p. 359) and managerial and professional capture (Smith et al. 2011). For example, Cooper and Owen (2014, p. 78) highlighted that management can strategically influence the assurance process. Management can select the assurance provider and restrict the topics of the assurance process. Based on a deductive content analysis of 61 assurance statements, Gürtürk and Hahn (2016, p. 35) noted that the majority of the assurance statements (87\%) omitted parts of the sustainability report and only assured selected topics or sections. In other words, management can restrict assurance processes to selected topics of a sustainability report that are most beneficial for the corporate image. Such an example of managerial capture reduces transparency and accountability at the expense of ethical assurance conduct (Hummel et al. 2019, p. 734).

Hasan et al. (2003) investigated the wording of assurance statements in the context of environmental reporting. They analyzed whether different limited assurance reporting forms (opinion on procedures, negative assurance, positive assurance, and positive assurance with a limitations paragraph) lead to significantly different perceptions by shareholders. Their findings show that assurance statement readers are able to recognize differences in assurance levels and risks. In a later study, Hasan et al. (2005) investigated the determinants and communication of different levels of assurance. Their research shows that companies use inconsistent 
Fig. 1 Signaling model of sustainability assurance, adapted from Connelly et al. (2011, p. 44)

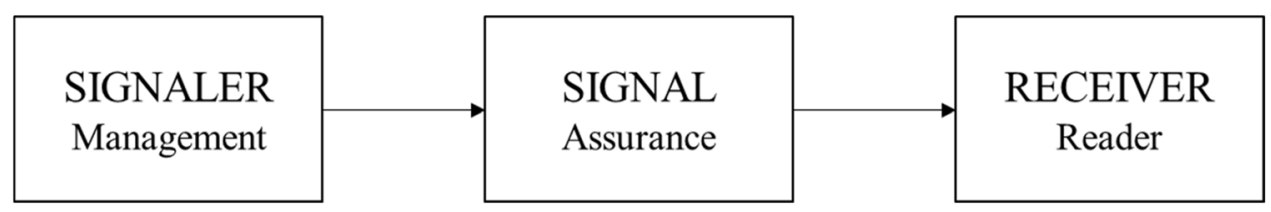

approaches to communicate limited assurance, and therefore readers have difficulties in differentiating between a high and limited level of assurance (Hasan et al. 2005, p. 100).

Hodge et al. (2009) built on a similar idea. They conducted an experimental study with 126 master's students in economics to compare different aspects of assurance (audited vs. unaudited, limited vs. reasonable assurance, accounting firm vs. specialist consultant) and analyzed whether the level of assurance is related to the perception of the credibility of a sustainability report. Contrary to Hasan et al.'s (2003) findings, report readers were not able to distinguish the difference between different levels of assurance. The authors were not able to find a significant effect on credibility for the level of assurance. However, the authors found a significant interaction effect for level of assurance and assurance provider.

To summarize, previous research on determinants and consequences of sustainability assurance have typically differentiated between firms with and without sustainability assurance. Some studies have also focused on additional assurance characteristics. In light of the fact that the vast majority of sustainability assurances are limited, it remains unclear how readers perceive differences in the choice of assured topics and the communication of this selection. By reflecting on signaling theory in an experimental approach, we aim to close this research gap. Given that prior research on the quality of the assurance process in terms of assurance process depth is inconclusive (Hummel et al. 2019), we extend this research field by investigating the communication of the conducted assurance processes (Gürtürk and Hahn 2016).

\section{Signaling Theory}

Previous studies have already highlighted the value of assurance as a signal in the context of financial reporting (e.g., Datar et al. 1991; Healy and Palepu 2001; Lys et al. 2015; Verrecchia 1983). We contribute to the limited number of studies discussing signaling theory with regard to the assurance of sustainability reports (e.g., Cheng et al. 2015; Clarkson et al. 2019; Hummel et al. 2019; Zerbini 2017) and thereby also follow a call to further build and expand signaling theory (Hahn and Reimsbach 2020).

It is a basic premise of signaling theory that the signaler wants to signal "quality" to the receiver. Signals of quality describe the "underlying, unobservable ability of the signaler to fulfill the needs or demands of an outsider observing the signal" (Connelly et al. 2011, p. 43). Transferred to the context of sustainability reporting, the management of the firm attempts to signal the credibility of their sustainability report (see Fig. 1).

Assurance can be regarded as a quality signal of the information provided by the firm, indicating information credibility and thereby counteracting an accusation of greenwashing (Cheng et al. 2015, pp. 136-137). Assurance can also reflect higher sustainability-related capital expenditures, therefore higher environmental performance (Zhou et al. 2016, p. 152) and higher future corporate value (Mock et al. 2007, p. 70).

Not only is information content signaled to the receiver but also information about the signaler's intent which can influence the perception of the receiver (Stiglitz 2000). For example, the mere decision of a firm to obtain assurance already signals that management is willing to reduce information asymmetries (Kausar et al. 2016).

The receiver as the second actor in the signaling model (see Fig. 1) is usually outside the firm and therefore lacks insider information (Connelly et al. 2011, p. 40; Spence 2002). While the signaler decides what and how to communicate to the receiver through the signal, the latter needs the information provided through the signal to be able to make a better informed decision (Connelly et al. 2011, p. 39 ). In the context of sustainability reporting, varied readers (reflected in different stakeholder groups; Morris 1997) receive assurance signals. They have to interpret the assurance signal to decide whether it increases the credibility of the information in the sustainability report. Mercer (2004, p. 186) defined disclosure credibility as "[investors'] perceptions of the believability of a particular disclosure." The perceived credibility of a sustainability report can influence subsequent stakeholder concerns and decisions, like risk and performance evaluations.

Signal costs are another important feature of signaling theory and are associated with firm costs to create the signal (Certo 2003, p. 434; Connelly et al. 2011, p. 52). This element of signaling theory is also important in the assurance context. Assurance statements are costly signals due to the payment of audit fees and the time and effort spent by management on preparing for and engaging in the assurance (Kausar et al. 2016). Organizations acquiring high-quality (i.e., costly) assurance services send a stronger signal to investors and other stakeholders (Cheng 
et al. 2015, pp. 136-137; Simnett et al. 2009). Following the notion of signaling theory, different levels of assurance reflect different signal costs. Therefore, comparisons of assurance costs and expected benefits also influence the requested depth of sustainability assurance (Casey and Grenier 2015, p. 98; Cohen and Simnett 2015, p. 62; Hummel et al. 2019, p. 737).

\section{Hypothesis Development}

\section{Credibility Hypothesis}

Although sustainability reports have received much scholarly attention, few studies have analyzed credibility perceptions of the reader beyond a conceptual level (Lock and Seele 2017, p. 585). However, the information in a sustainability report will only be relevant and useful for stakeholders if it is perceived as credible. Dando and Swift (2003) identified a "credibility gap," in which low levels of public trust and confidence undermine the value of corporate reporting. Michelon et al. (2015, p. 59) explained the reasons for the credibility gap as a lack of completeness and quality of the disclosure. Boiral et al. (2019) referred to biased and overly positive reporting in sustainability reports as an additional reason for the low credibility of sustainability reports. Indeed, sustainability reports are often perceived as marketing tools used to present a favorable picture of the organization and to strengthen the firms' legitimacy and reputation (Hahn and Lülfs 2014, p. 402). In this context, sustainability assurance can be used to lower the credibility gap through its function as a quality signal. Indeed, empirical studies confirm a positive relation between sustainability assurance and credibility (Kolk and Perego 2010; Simnett et al. 2009). To the contrary, Kuruppu and Milne (2010) reported mixed evidence of assurance on beliefs about the credibility of the presented information.

As sustainability reports are mainly communication instruments of the firm (Hooghiemstra 2000), we refer to the credibility construct following the Habermasian theory of communicative action (Habermas 1984). Lock and Seele (2017) provided a new measurement of the "multidimensional perception construct" of credibility (p. 586), referring to Habermas's ideal speech situation and operationalizing it in four sub-dimensions (p. 585). According to Habermas (1984), the validity claims of the ideal speech situation are fulfilled when the information is true (truth), the speaker is sincere (sincerity), the communication is appropriate in its normative context (appropriateness), and understandable to the reader (understandability).

Sustainability assurance by an independent third party improves disclosure quality and increases the probability of finding misstatements and omissions (Hodge et al. 2009, p. 181). When readers, as the receivers of the signal, perceive sustainability assurance as a positive quality signal, it should result in a higher credibility evaluation compared to cases in which no sustainability assurance is provided. This leads to the following hypothesis:

Credibility Hypothesis ( $\mathrm{H} 1)$ Report readers perceive an assured sustainability report as more credible than a sustainability report without any assurance.

\section{Reference Explicitness Hypothesis}

Following signaling theory, one of the most important characteristic of efficacious signals is signal observability ${ }^{5}$ (Connelly et al. 2011, p. 45). Signal observability "refers to the extent to which outsiders are able to notice the signal" (Connelly et al. 2011, p. 45). Accordingly, signals can be characterized by how easily they can be detected by the receiver (Connelly et al. 2011, p. 53). In the context of sustainability assurance, signal observability can be captured by reference explicitness. Reference explicitness refers to the communication choice of assurance and differentiates whether a firm indicates an assured topic via visual or verbal information cues. We argue that a visual assurance signal is more observable than a verbal one. Additional visual information cues are a form of visual emphasis (Merkl-Davies and Brennan 2007), thus the information is more salient for readers of a sustainability report (Djamasbi et al. 2011; Jarvenpaa 1990). Furthermore, visual formats are more likely to direct the reader's attention to the information presented (Hellmann et al. 2017; Lurie and Mason 2007), consequently readers will be able to notice an explicit assurance signal more easily.

In assessing the relationship between reference explicitness and the perception of credibility, we underline how important it is that the reader observes and consciously receives the assurance signal.

An unclear reference can create the impression of an overall assured sustainability report, even though only selected topics have been assured. This concern is also shared by the Institute of Public Auditors in Germany (IDW 2018, p. 4): "Audited and unaudited report elements smoothly merge and are hardly identifiable from each other to the external addressee during reading. [...] Report recipients may easily lose track and consider unaudited information

\footnotetext{
${ }^{5}$ In our manuscript, we define signal observability as the "extent to which outsiders are able to notice the signal." We follow the terminology used by Connelly et al. (2011, p. 45). For the sake of completeness, however, it should be noted that in signaling literature, different terms are used to describe similar signal characteristics (Connelly et al. 2011, p. 52). For example, the way Ramaswami et al. (2010) used the term signal visibility corresponds with the definition applied for signal observability by Connelly et al. (2011, p. 53). Gao et al. (2008) have used the term signal intensity to describe similar characteristics of signal observability. In the described examples, the terms describe the same concept and can be used interchangeably.
} 
to be audited."6 If readers are unable to distinguish between assured and non-assured topics, they consequently cannot evaluate the assurance signal correctly. This can lead to an incorrect assessment of the credibility of the sustainability report as such.

On investigating this relationship, we refer to an experimental study by Hodge (2001). In this study, participants received a financial statement (assured information) and a letter to shareholders (non-assured information). It became clear that investors wrongly classified the non-assured information as assured information. This led to an overestimation of the credibility of the non-assured information and increased the credibility of the entire information set. Hodge (2001, p. 679) refers to this phenomenon as the credibility inflation effect. We assume that when readers of a sustainability report cannot easily distinguish between assured and non-assured information, this can create a comparable credibility inflation effect.

An accurate, observable, and unambiguous assurance signal should primarily reduce the risk of confusion between assured and non-assured information. When readers in principle are able to differentiate between assured and nonassured information, an explicit reference provides higher transparency of the assurance process and creates higher perceived credibility of the sustainability report. This leads to the following hypothesis:

Reference Explicitness Hypothesis (H2) Readers of sustainability reports are more likely to perceive the credibility of sustainability reports as higher if the reference to the assurance is made explicitly.

\section{Assurance Depth Hypothesis}

Previous studies have found that in practice there is a substantial variation in the quality of sustainability assurance. Fonseca (2010, p. 359) attributed this to "ambiguity and diversity in criteria and scope," whereas Bagnoli and Watts (2017, pp. 205-206) referred to inter alia differences in assurance depth.

Especially for limited assurance, management has some leeway to select the topics to be assured. Specifically, a firm could decide to obtain sustainability assurance for topics in which it performs exceptionally well (O'Dwyer 2011, pp. 1249-1250). If companies only assure parts of their sustainability reports, this limits transparency and accuracy (Gürtürk and Hahn 2016, p. 38) and does not contribute to closing the aforementioned credibility gap (Dando and Swift 2003).

In the words of signaling theory, a firm can send readers the signal of assurance, even though only selected topics

\footnotetext{
${ }^{6}$ Direct translation from German to English by the authors.
}

have been part of the scope of assurance. Consequently, the quality of sustainability assurance as a signal can vary considerably. In terms of signaling theory, we address this issue within the boundaries of signal fit. Signal fit reflects the "extent to which the signal is correlated with unobservable quality" the signaler wants to convey (Connelly et al. 2011, p. 52). In other words, signal fit expresses how well the signaling firm fulfills the quality claim it communicates with the signal. For sustainability assurance, signal fit is highly dependent on the performed assurance engagement. We contribute to the debate on assurance depth because firms can particularly influence this element of sustainability assurance (Hummel et al. 2019, p. 734).

A reduction in assurance depth, without adapting the signal, reduces the underlying quality of the assurance signal. As the signal does not fulfill an equal quality claim, such a change in signal fit should influence credibility perceptions of readers of a sustainability report. We argue that a higher signal fit leads to higher perceived credibility of the sustainability report as reflected in the following hypothesis:

Assurance Depth Hypothesis (H3) Readers of sustainability reports are more likely to perceive the credibility of sustainability reports as higher if the assurance depth is high.

\section{Interaction Hypothesis}

For a sustainability report to be of value, the provided information has to be perceived as plausible and trustworthy (Hahn and Kühnen 2013, p. 14). If a firm uses sustainability assurance as a quality signal for the sustainability report, the assurance itself must be credible (Watson et al. 2002, p. 201).

While true quality is reflected in a credible signal, signaling theory refers to the behavior of "false signaling" if the signaler does not possess the signaled quality but intentionally sends a misleading signal to the receiver (Connelly et al. 2011 , p. 45). In such cases, the signaler takes advantage of existing information asymmetries and tries to influence the receiver's decision to his or her own benefit. In the context of selected sustainability assurance, a firm would send the signal of an assured sustainability report, although not all topics have been subject to assurance. Organizations can take credit for a positive signaling effect, despite having only low assurance depth. The underlying assumption is that, regardless of the applied assurance depth, the mere provision of assurance is sufficient as a signal for receivers (Hummel et al. 2019, p. 738). Readers will perceive the sustainability report as unjustifiably more credible if they do not detect the false signal.

However, receivers can also detect false signaling and impose penalty costs, which are negative reactions of 
Fig. 2 Experimental betweensubjects design
Reference explicitness

\begin{tabular}{|c|c|c|c|}
\cline { 3 - 4 } \multicolumn{1}{c|}{} & High & Low \\
\cline { 2 - 4 } & Assurance depth & Treatment 1 & Treatment 2 \\
\cline { 2 - 4 } & Low & Treatment 3 & Treatment 4 \\
\hline
\end{tabular}

receivers (e.g., negative feedback, consumer boycott, lawsuits; Connelly et al. 2011, p. 61; Gammoh et al. 2006, p. 467). In the context of sustainability assurance, penalty costs are mainly expressed through lower perceived credibility. Once false signals are revealed, they are no longer effective (Alon and Vidovic 2015, p. 340) and subsequent signals will also not be seen as credible (Watson et al. 2002, p. 291).

The relevance of false signaling in the context of sustainability assurance is documented in several academic studies (e.g., Cho et al. 2015; Maroun 2020; Michelon et al. 2015). Findings by Michelon et al. (2015, p. 75) showed that firms do not use assurance as a substantive practice but rather as an instrument to demonstrate sustainability commitment. Maroun (2020) criticized sustainability assurance due to its lack of detail and precision, and Cho et al. (2015) noted that many firms approach sustainability issues on a symbolic level. While independent assurance should alleviate stakeholder concerns regarding corporate greenwashing (Lyon and Maxwell 2011), assurance itself can be misused as a symbolic practice (Michelon et al. 2015). Therefore, Maroun (2020) reasoned that sustainability assurance can also be interpreted as an impression management process.

We argue that the likelihood of the receiver to detect a false signal is influenced by the combination of reference explicitness and assurance depth of the sustainability assurance. To illustrate our point, we refer to assurance signals with low reference explicitness as an example. Potential penalty costs in such a case are lower, as false signaling is not as easily detectable as it is for highly observable signals. On the contrary, false signaling is successful if the firm intentionally combines low reference explicitness and low assurance depth and readers falsely perceive an increased credibility of the sustainability report. Such a cherry-picking behavior of firms, when setting the communication and topic choices of sustainability assurance, creates ethical tensions. It contradicts ethical assurance practices in terms of accountability and transparency. Nevertheless, in the short run, it could positively influence credibility perceptions of sustainability report readers. However, in the long run, applied practices of false signaling might damage the credibility of sustainability assurance as such. To find out how readers react to variations in communication and topic choices, we investigate all different combinations of assurance depth and reference explicitness. This leads to the following hypothesis:

Interaction Hypothesis (H4) Credibility perceptions will differ based on the interaction of assurance depth and reference explicitness.

\section{Research Method}

\section{Overview of Experimental Design}

This study is based on a $2 \times 2+1$ between-subjects design in which participants were asked to evaluate the credibility of the sustainability report of a fictitious textile company. Between treatment groups (see Fig. 2), we randomly manipulated (1) reference explicitness (low vs. high) and (2) assurance depth (low vs. high) of an attached assurance report. In all conditions, the content of the sustainability report and the sustainability performance of the fictitious company remained constant. This experimental design resulted in four different treatment groups plus an additional control group that evaluated the sustainability report without any assurance. Except for the control group, all assurance reports were subject to a limited level of assurance.

\section{Participants and Experimental Materials}

Participants in our experimental design are postgraduate students in business who proxy for reasonably informed non-professional investors, as one group of sustainability report readers. Non-professional investors have become a significant element in financial markets, and they are an important target stakeholder group for sustainability reporting (Cohen et al. 2011; Hellmann et al. 2017; Reimsbach and Hahn 2015). Using student participants is justified because our experimental task does not entail high integrative complexity (Elliott et al. 2007). For example, assessing the credibility of a sustainability report does not require participants to draw complex connections. Additionally, 
business graduate students often proxy for non-professional investors in experimental studies (e.g., Cheng et al. 2015, p. 141; Hellmann et al. 2017; Libby et al. 2002).

We asked participants to complete an online questionnaire via Qualtrics, and distributed the survey link to participants enrolled at universities in Germany and Australia. We relied on advertisements, which were communicated in the classes at the universities, to recruit participants. Following the advertisement, 220 participants commenced with the questionnaire in class. From those, 157 participants completed the questionnaire, which represents a dropout rate of 0.29 .

The experiment started with some general instructions and background information for participants. The textile company $\mathrm{ABC}$ was presented, listing the material topics (see Appendix 1). The remaining part of the questionnaire consisted of three sections. The first section contained a short excerpt of a sustainability report, comprising two environmental and two social sustainability topics and (except for the control group) an assurance report (see Appendix 2). Depending on participants' treatment groups, they were randomly shown a report with different communication and topic choices of sustainability assurance. The sustainability and the assurance report presented identical information; the sole difference between them was the depth of the assurance performed and the way assurance was referenced.

While disclosed negative information is per se more credible (Cho et al. 2013), prior studies have demonstrated the dominance of positive information in sustainability disclosure (e.g., Holder-Webb et al. 2009; Lougee and Wallace 2008). We presented a sustainability report with overly positive performance for all treatment conditions. In this case, credibility of the sustainability-related information is not very high and assurance is necessary to increase the level of credibility. The sustainability report was anonymized to control for potential bias for or against specific brands. However, the descriptions of the sustainability topics were based on GRI Standards (2018) and sustainability reports of real companies in the textile sector. As the value chain in the apparel and textile industry is oftentimes outsourced to manufacturers and suppliers in emerging markets, this sector is heavily intertwined with environmental, social, and governance issues (SASB 2015). This industry sector has also received wide scholarly attention, especially due to past sustainability scandals (Köksal et al. 2017; Oelze 2017).

The second section consisted of the credibility evaluation of the participants. To measure the perceived credibility, we used an adaptation of the perceived credibility scale developed by Lock and Seele (2017).

The third section (the post-experimental questionnaire) contained a number of questions to check attention and manipulation. ${ }^{7}$ We measured a set of control variables (familiarity with sustainability reporting, English proficiency), including demographic questions (gender, nationality, topic area of degree). We used 7-point Likert-type scales to measure the control variables, which were anchored at $1=$ very unfamiliar/low to $7=$ very familiar/high.

\section{Experimental Variables}

\section{Reference Explicitness}

In our experiment, we operationalized the independent variable reference explicitness by using visual or verbal information cues when communicating sustainability assurance. The assured topics of the sustainability report were either marked with a more explicit visual graphical reference (high reference explicitness) or indicated less explicitly in a verbal text form within the assurance report (low reference explicitness).$^{8} \mathrm{~A}$ graphical reference in proximity to the topics assured entails a higher visual salience than a verbal format. ${ }^{9}$

Such visual formats have been used in sustainability assurance practice, for example, by the German insurance company Allianz (2016). We aim to analyze how different references to indicate the assured parts of a sustainability

\footnotetext{
${ }^{7}$ We asked participants to evaluate the sustainability performance of $\mathrm{ABC}$ relative to the industry average. Participants who evaluated the performance higher than 3 on a 7-point Likert-type scale (which was anchored at $1=$ very low to $7=$ very high) were coded as correct answers. Additionally, we asked participants further attention and manipulation checks: They had to recall which of the presented sustainability topics were considered the two most important ones for $\mathrm{ABC}$ and its stakeholders. They had to indicate which topics had been externally assured and to select how the company provided an indication of the topics that were part of the scope of the sustainability assurance. Of the participants, $83.3 \%$ answered at least two of the attention and manipulation check questions correctly.

8 While the terms "lower" and "higher" would underline that the categories are relative to each other, we prefer to use the categories "low" and "high" to strengthen the difference between manipulations and to facilitate interpretation.

${ }^{9}$ Visual information formats can be a more powerful means of communication than text only, because of their ability to attract attention and convey emotions with simplicity (Ang et al. 2020; Kanbaty et al. 2020). Findings in the domain of cognitive psychology showed that visual communication is more easily recalled and memorized than verbal information (e.g., Kaplan et al. 1968; Lutz and Lutz 1978; Paivio 1969; Paivio et al. 1968; Sampson 1970; Thomas 1983). For example, a study by Sundar and Kellaris (2017) focused on the mode of presentation of eco-friendly logos and also differentiated between visual and verbal information cues. In the context of eco-labels, their visibility is considered an important attribute "to attract the attention of the customer" (Taufique et al. 2014, p. 2185). However, other studies documented that visual information is not always superior compared to verbal information (Childers and Houston 1984; David 1998). These studies found that the superiority of visual information is context dependent and conditional, for example, on the concreteness of the verbal information.
} 
Table 1 Adapted PERCRED scale by Lock and Seele (2017)

\begin{tabular}{|c|c|}
\hline $\begin{array}{l}\text { Sub-dimensions of validity } \\
\text { claim }\end{array}$ & Final statements \\
\hline Accuracy & I think that the statements in the sustainability report are accurate. \\
\hline Truthfulness & I am confident that the statements in the sustainability report are true. \\
\hline Intentions & I think that the company's intentions correspond with the sustainability report. \\
\hline Trustworthiness & The sustainability report is misleading. \\
\hline Norms & $\begin{array}{l}\text { The sustainability report fits to the context of the textile industry and its } \\
\text { social and environmental challenges. }\end{array}$ \\
\hline Context & $\begin{array}{l}\text { As a reader of this sustainability report, I feel that the report addresses the } \\
\text { presented sustainability issues well. }\end{array}$ \\
\hline Legitimacy & I think the sustainability report rightfully represents the company. \\
\hline
\end{tabular}

report are perceived by the readers of these reports. This contributes to two empirical studies investigating the use of symbols in communicating sustainability assurance. Mock et al. (2007) and Mock et al. (2013) found that 13 out of 130 companies (10\%) in the period from 2002 to 2004 and 9 out of 148 reports (6\%) in the period 2006-2007 used symbols instead of words to indicate assured statements. We follow Mock et al. (2007, p. 71) who first describe this communication method and different designs of such symbols. Typically, the symbol is placed next to the statement or section in the sustainability report that had been assured. In a more recent study, Gürtürk and Hahn (2016, p. 35) noted that 13\% of the 61 analyzed assurance statements used symbols to indicate which information in the report was assured. Such a reference can assist the reader in distinguishing between assured and non-assured topics and "is critical to ensure the user is not misled" (Mock et al. 2007, p. 71). Symbols are used to draw readers' attention to key data and facts in a sustainability report (Mock et al. 2013, p. 287). Symbols can be used in both limited and reasonable assurance levels. However, to mark the assured topics, they are more useful in cases in which only selected topics are assured. Such symbols should serve, above all, as a clear and transparent communication of the sustainability assurance conducted (Mock et al. 2013, p. 290). It is thus surprising that only a small number of firms use symbols in their sustainability reports.

In the operationalization of reference explicitness, we have chosen a visual graphical reference in the form of a symbol (green tick) to extend the literature on sustainability assurance communication. Directly placed next to the assured topics, the symbol might serve as an additional information cue to direct the reader's attention to the assured sections.

\section{Assurance Depth}

We manipulated the second independent variable, assurance depth, by varying the assured topics of a sustainability report. In their empirical analysis, Hummel et al. (2019, pp. 743-744) derived the variable assurance process depth from qualitative research, which refers to the content of assurance statements. They thereby measured assurance depth based on the elements of scope, methods, level, materiality, recommendations, and coverage. In our experiment, we left the above-mentioned elements constant and modeled assurance depth by the choice of material vs. non-material topics in the conducted sustainability assurance. We applied the definition of material topics provided by the GRI $(2018,101$ : 1.3.1), that "reflect the reporting organization's significant economic, environmental, and social impacts [or] substantively influence the assessments and decisions of stakeholders." In the high assurance depth treatments, the assured topics were equivalent to the aforementioned material topics, while in the low assurance depth treatments, only the non-material topics were assured. The selection of material topics for the fictitious textile company was based on a sector evaluation by the Governance \& Accountability Institute (G\&A 2014) and the GRI publication "Sustainability topics for sectors" (2013).

\section{Perceived Credibility}

Our dependent variable captures readers' perceived credibility of the sustainability report. We adapted the aforementioned perceived credibility scale (PERCRED) developed by Lock and Seele (2017) to our setting (see Table 1). ${ }^{10}$

The adapted PERCRED scale comprises seven 7-point Likert scale statements. The Likert scales were anchored at $1=$ strongly disagree to $7=$ strongly agree. Trustworthiness was captured by a reverse-coded statement (S7). PERCRED was calculated as the average of the seven statement scores and has a Cronbach's alpha value of 0.82 .

\footnotetext{
${ }_{10}$ While Lock and Seele (2017) developed a scale to analyze stakeholders' credibility perceptions of corporate social responsibility communication, we use an adapted version of the scale to investigate credibility perceptions of assured sustainability reports. Our statements to measure perceived credibility are based on seven of the fifteen items in the original version. In our statements, we explicitly refer to the "sustainability report," while Lock and Seele (2017) referred to the credibility of the "text."
} 


\section{Results}

\section{Descriptive Statistics}

In total, we collected 157 responses. Two observations were excluded from the sample due to their low proficiency score in English. ${ }^{11}$ After eliminating another five outliers from our data, we proceeded with a final sample size of $150 .{ }^{12}$

Participants were randomly assigned to one of the five treatments. Therefore, participant characteristics such as gender $($ women $=51 \%)$, nationality $(28 \%$ German, $27 \%$ Chinese, $22 \%$ Australian, and 23\% other), and different general topic areas of their postgraduate degree (42\% Business Administration, $15 \%$ Accounting, $15 \%$ Economics, $13 \%$ Commerce, $8 \%$ Finance, $4 \%$ International Business and Sustainability, and $3 \%$ other) were also randomly distributed across the treatments. Post-experiment analysis showed no significant differences in responses across the treatment groups, indicating that the randomization process was successful. Additionally, we included additional control variables (i.e., familiarity with sustainability reporting, English proficiency, gender, nationality, topic area of degree) in our analyses and found no considerable changes regarding our main results.

Table 2 depicts the cell means and standard deviations for the dependent variable, perceived credibility, and the number of participants in each treatment.

\section{Hypothesis Testing}

The credibility hypothesis (H1) was tested using a one-way ANOVA. We compared the responses for the dependent variable of perceived credibility between the participants who received an assured sustainability report (Treatments 1 through $4 ; n=118$ ) and those that did not receive any assurance (Treatment $5 ; n=32$ ). Table 3 presents the descriptive statistics, while Table 4 Panel A summarizes the results of the one-way ANOVA. Although in the predicted direction, the difference

\footnotetext{
11 A 7-point Likert scale rating ranging from $1=$ very low to $7=$ very high was used for participants' self-evaluation of English proficiency. Participants scoring one or two were eliminated from the analysis.

12 To identify outliers, we used box-and-whisker diagrams (Tukey 1977) based on the residuals of the factorial ANOVA for the dependent variable perceived credibility. A box is drawn from the first quartile to the third quartile of the data points in the sample. As boxplots help to display data points which fall more than 1.5 box lengths from the lower or upper hinge of the box (Parke 2015, pp. 83-84; Rousseeuw and Hubert 2011, p. 74), we identified five observations based on the mean value of perceived credibility for each treatment group.

Data cleansing is the basis for data analysis and serves to reduce errors when generating new scientific insights. Our results prove that data cleansing was successful: when we included the two outliers for English proficiency and the five outliers for perceived credibility in our analysis, our results remained directionally equivalent, while we lost significance in the interaction effect.
}

Table 2 Summary statistics

\begin{tabular}{lllll}
\hline Dependent variable: perceived credibility & & & \\
\hline & & Mean & SD & $N$ \\
\hline $\begin{array}{l}\text { Low assurance } \\
\text { depth }\end{array}$ & Low reference explicitness & 4.49 & 0.835 & 29 \\
& & & & \\
& High reference explicitness & 4.65 & 0.996 & 30 \\
High assurance & Total & 4.57 & 0.916 & 59 \\
depth & Low reference explicitness & 4.86 & 0.752 & 28 \\
& & & & \\
& High reference explicitness & 4.24 & 1.009 & 31 \\
Total & Total & 4.54 & 0.943 & 59 \\
& Low reference explicitness & 4.67 & 0.811 & 57 \\
Control & High reference explicitness & 4.44 & 1.015 & 61 \\
Total & No assurance & 4.50 & 0.889 & 32 \\
\hline
\end{tabular}

Table 3 Credibility hypothesis-descriptive statistics

\begin{tabular}{llll}
\hline Dependent variable: perceived credibility & & \\
\hline & Mean & SD & $N$ \\
\hline No assurance & 4.50 & 0.889 & 32 \\
Assurance & 4.55 & 0.926 & 118 \\
Total & 4.54 & 0.915 & 150 \\
\hline
\end{tabular}

in means for perceived credibility is not statistically significant $(F=0.10, p=0.08)$. Independent sample $t$ tests showed a statistically significant difference in the mean perceived credibility score between the high assurance depth and low reference explicitness condition (Treatment 2) and the control group $(t(58)=1.711, p=0.09)$. All other $t$ tests remained insignificant (see Table 4 Panel B). Therefore, the credibility hypothesis is not supported, with the exception of Treatment 2.

We tested $\mathrm{H} 2, \mathrm{H} 3$, and $\mathrm{H} 4$ using a factorial ANOVA. We thereby analyzed responses for all five groups because a $2 \times 2+1$ between-subjects design was used with assurance depth and reference explicitness as the two factors. Table 5 summarizes the results of the ANOVA for the main and the interaction effects. It can be seen that neither assurance depth $(F=0.01, p=0.92)$, nor reference explicitness $(F=1.93$, $p=0.17)$ significantly impact perceived credibility. Hence, there is no support for the reference explicitness hypothesis (H2) and the assurance depth hypothesis (H3). However, Table 5 shows a significant interaction between assurance depth and reference explicitness $(F=5.51, p=0.02)$ which provides support for the interaction hypothesis (H4). To further interpret the interaction effect, we performed a simple effects analysis (Table 6).

The simple effect of perceived credibility was significant for high assurance depth $(F=6.97, p<0.01)$ but not for 
Table 4 Credibility hypothesis-results

Dependent variable: perceived credibility

Panel A: One-way ANOVA

\begin{tabular}{llllll}
\hline & SS & df & MS & $F$ ratio & $p$ value \\
\hline Between groups & 0.080 & 1 & 0.080 & 0.095 \\
Within groups & 124.731 & 148 & 0.843 & & \\
Total & 124.811 & 149 & & \\
\hline
\end{tabular}

Panel B: Independent samples $t$ tests

\begin{tabular}{llll}
\hline & $t$ & df & $p$ value \\
\hline Control vs. Treatment 1 & -1.069 & 61 & 0.289 \\
Control vs. Treatment 2 & 1.711 & 58 & $0.092^{*}$ \\
Control vs. Treatment 3 & 0.635 & 60 & 0.528 \\
Control vs. Treatment 4 & -0.035 & 59 & 0.972 \\
\hline
\end{tabular}

This table presents the results of the one-way ANOVA in Panel A. We report the results for independent samples $t$ tests in Panel B. Treatment 1 refers to high assurance depth and high reference explicitness, Treatment 2 refers to high assurance depth and low reference explicitness, Treatment 3 refers to low assurance depth and high reference explicitness, and Treatment 4 refers to low assurance depth and low reference explicitness

$*, * *, * * *$ indicate significance at the 10,5 , and 1 percent levels, respectively (two-tailed)

Table 5 Factorial ANOVA-results

Dependent variable: perceived credibility

\begin{tabular}{lrllll}
\hline Source & SS & Df & MS & $F$ ratio & $p$ value \\
\hline Assurance depth & 0.008 & 1 & 0.008 & 0.010 & 0.920 \\
Reference explicitness & 1.577 & 1 & 1.577 & 1.927 & 0.167 \\
Assurance depth $\times$ Ref- & 4.510 & 1 & 4.510 & 5.513 & $0.020^{* *}$ \\
$\quad$ erence explicitness & & & & & \\
Error & 118.616 & 145 & & & \\
Total & 3216.551 & 150 & & & \\
\hline
\end{tabular}

$*, * *, * * *$ indicate significance at the 10,5 , and 1 percent levels, respectively (two-tailed)

low assurance depth $(F=0.46, p=0.50)$. The simple effect for high reference explicitness was significant $(F=3.10$, $p=0.08)$, while it is insignificant for low reference explicitness $(F=2.44, p=0.12)$. Figure 3 graphically depicts the effects of this interaction. The results suggest that in situations in which firms obtain assurance for material topics (high assurance depth), report readers perceive the credibility of the sustainability report higher when such assurance is marked verbally $(M=4.86)$ rather than provided via a visual graphical reference $(M=4.24)$. No such difference between reference explicitness was found for low assurance depth
Table 6 Simple effects analysis-results

\begin{tabular}{llllll}
\hline Dependent variable: perceived credibility & & \\
\hline Source & SS & df & MS & $F$ ratio & $p$ value \\
\hline Low assurance depth & 0.377 & 1 & 0.377 & 0.461 & 0.498 \\
High assurance depth & 5.703 & 1 & 5.703 & 6.972 & $0.009^{* * *}$ \\
Low reference explicitness & 1.999 & 1 & 1.999 & 2.443 & 0.120 \\
High reference explicitness & 2.538 & 1 & 2.538 & 3.102 & $0.080^{*}$
\end{tabular}

We used Bonferroni adjustment for multiple comparisons $*, * *, * * *$ indicate significance at the 10,5 , and 1 percent levels, respectively (two-tailed)

( $M=4.65$ and $M=4.49$ for the visual and verbal treatments, respectively). As we did not measure higher credibility perceptions for the combination of low assurance depth and high reference explicitness, we could not verify that false signaling creates the intended effect of increased credibility perceptions by readers.

To test the robustness of the interaction effect, we compared the result for the dependent variable PERCRED to the item level. While the interaction effect is directionally equivalent for four items, we measured a significant interaction effect for three items. 
Fig. 3 Graphical representation of the results

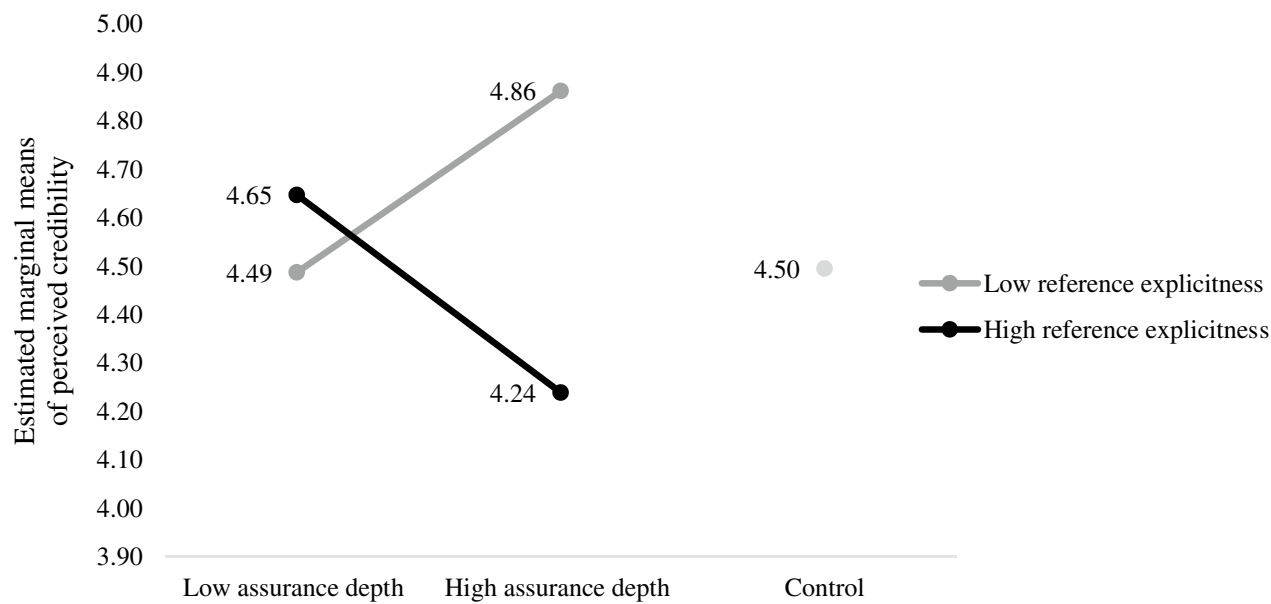

\section{Discussion}

We examined the role of the two strategic choices, reference explicitness and assurance depth, of sustainability assurance in influencing how readers perceive the credibility of a sustainability report. The results indicate that neither reference explicitness nor assurance depth alone determine the perceived credibility of sustainability reports. However, as the significant interaction effect of both factors show, perceived credibility differs, depending on the combination of the independent variables assurance depth and reference explicitness.

To further discuss the interaction effect (H4), we have a look at all different factor combinations (see Fig. 3). Related to the non-confirmation of $\mathrm{H} 1$, sustainability report readers in the low assurance depth treatments perceived the information similarly credible as in the no assurance condition (control group). Therefore, this strategic topic choice (low assurance depth) does not produce the desired increase in perceived credibility. We observe that assurance can only add credibility on the sustainability report if it is based on high assurance depth (i.e., including the material topics). This observation leads to the recommendation that firms should refrain from obtaining sustainability assurance if they do not intend to assure their material topics.

When we add the factor dimension of the communication choice, we observe that in situations in which assurance is marked less explicitly in a verbal form, readers perceive the sustainability report as more credible for high assurance depth than for low assurance depth. Perceived credibility in the low reference explicitness condition was measured in the predicted direction of the assurance depth hypothesis (H3). However, if the firm indicates assured topics via a visual graphical reference, perceived credibility evaluations react inversely. Our results suggest that for high assurance depth, the presence of high reference explicitness is harmful to the perceived credibility of a sustainability report. Compared to our predictions in the reference explicitness hypothesis (H2), these results appear counter-intuitive. They therefore require further theoretical analysis against the background of signaling theory.

In the hypothesis development, we argued that credibility perceptions vary depending on receivers' ability to detect false signals. While a good signal fit indicated by a less observable signal (high assurance depth and low reference explicitness) is perceived as a true and credible signal, a highly observable signal (high reference explicitness) might be (wrongly) perceived as a false and, therefore, not a credible signal. Although a visual graphical indication of assured material topics is not designed to be a false signal in our setting, readers seemed to interpret it as such.

A relevant concept in this context is "receiver interpretation" (Connelly et al. 2011, p. 52). Receiver interpretation describes the process of receivers translating signals and putting meaning to them (Connelly et al. 2011, p. 54). This process is not error-free, as distortions or individual weights can influence its outcome. Receivers might not interpret signals uniformly (Perkins and Hendry 2005; Srivastava 2001), depending on their individual background, changing instrumental and symbolic inferences (Highhouse et al. 2007), or personal values, external 
pressures, and necessities (Branzei et al. 2004, p. 1091). Previous research has demonstrated the importance of the receiver's perspective in order to understand signaling processes (Suazo et al. 2009; Turban and Greening 1997). Based on the subjective information available to individuals (Ehrhart and Ziegert 2005, p. 903), receivers may interpret signals by departing from the original intent of the signaler.

In our setting, an explicit visual indication of assured sustainability topics (high reference explicitness) seems to be interpreted as a false signal. A visual graphical reference apparently does not increase the level of comprehensiveness and transparency of sustainability assurance. Our results indicate that participants could perceive a visual graphical reference as a misleading or too influential signal and therefore react with penalty costs (Connelly et al. 2011, p. 61) in the form of lower credibility perceptions. Our findings might explain the low prevalence of visuals (e.g., symbols) to indicate assured content within sustainability reports, as observed by Gürtürk and Hahn (2016, p. 35).

When interpreting the findings of our paper, we have to carefully consider factors which affect the reliability and generalizability of our experiment. With regard to experimental control, the amount of information provided to the participants was limited to avoid confounding factors and to increase the attention paid to the independent variables reference explicitness and assurance depth. We paid attention to create a setting for sustainability report readers that is structurally equivalent to a real-world setting, while isolating two strategic decisions around sustainability assurance. Although we believe that our research design adequately captures the signaling process of sustainability assurance, in practice readers consult various information channels when assessing the credibility of disclosure (Mercer 2004). Potential investors might consult additional sources of information, such as further reports, ratings, or social media, which might influence their credibility perceptions (Hahn et al. 2019). As our focus lies on non-professional investors, this reader group is likely more open when assessing sustainability assurance but also more prone to react to false signaling. In contrast, professional investors and auditors with experience in evaluating assurance are more likely to detect false signaling because they may have developed strategies against cognitive biases. For example, Maines and McDaniel (2000) argue that analysts are more focused on the content than the presentation format of financial statements.

Summarizing, assigning assurance to selected topics has to be done with caution. Companies have to be aware that a restriction of assurance depth might harm transparency of sustainability assurance. Furthermore, a well-intended high reference explicitness in the form of a graphical indication of assured topics might create unexpected and unwanted reader reactions to a sustainability report. If readers mistakenly consider it as a false signal, they will react with penalty costs and lower credibility perceptions.

\section{Conclusion}

Our experimental study provides empirical evidence supporting the relevance of different assurance choices for the perceived credibility of sustainability reports. It also provides support for the argument that the interaction between reference explicitness and assurance depth should be considered in sustainability assurance practice as it leads to different and sometimes unintended reader reactions.

We contribute to the literature in several ways. First, we extend prior studies on sustainability assurance by examining the practice of assuring only selected topics of a sustainability report. Our research differs from previous studies in this domain (e.g., Fuhrmann et al. 2017; Hodge et al. 2009; Manetti and Becatti 2009; Maroun 2020; Perego and Kolk 2012), because we use an experimental approach with an explicit focus on the reduction of assurance depth. Our findings indicate that sustainability assurance only increases credibility perceptions if it includes the material topics of a report. Firms should therefore consider our results in their cost-benefit considerations when assigning sustainability assurance. Second, we add to the few studies that explicitly consider reference explicitness of assurance (Gürtürk and Hahn 2016; Mock, Rao and Srivastava 2013; Mock, Stohm and Swartz 2007). Our experimental design allows us to analyze different degrees of reference explicitness in the communication of sustainability assurance. Our findings demonstrate that auditors have to be careful about how to mark the assured topics. A graphical reference can be wrongly interpreted by readers and, therefore, lead to lower credibility perceptions. To protect organizations from negative effects of such misinterpretation, sustainability assurance of selected topics should be communicated in an unambiguous form to readers of assurance and sustainability reports. Third, we contribute to literature on managerial capture (Hummel et al. 2019; Owen et al. 2000; Smith et al. 2011) by analyzing the interaction effect of reference explicitness and assurance depth. Selecting assured topics and not communicating that choice in a transparent form is a managerial 
decision that requires critical ethical analysis. Such false signaling can potentially distort readers' credibility perceptions of the sustainability report. As readers of sustainability reports do not positively react to a lower signal fit, our results show that false signaling is not only an unethical but also an unsuccessful practice. Fourth, our paper contributes to the growing research on the signaling role of assurance in sustainability reporting (e.g., Cheng et al. 2015; Clarkson et al. 2019; Hummel et al. 2019; Zerbini 2017). In line with the call to build on and extend signaling theory (Hahn and Reimsbach 2020), our findings extend literature on signaling theory by showing that signal observability and signal fit (Connelly et al. 2011) are relevant aspects in the context of sustainability assurance. Although they do not affect perceived credibility when applied separately, they interact when appearing jointly. Different levels of signal observability influence the perceived credibility of signals that show high signal fit. Consequently, signal observability can influence signal interpretation by readers. Our results provide evidence for cases of misinterpreted signaling in which high signal observability and high signal fit lead to a decrease in perceived credibility. Therefore, our findings provide new insights against the background of signal interpretation. For high reference explicitness, we were able to demonstrate an incorrect signal interpretation by readers.

Beyond limitations typically associated with experimental research, the results of our study should be interpreted with caution in light of the following limitations. First, the study was based on master's students in business as a proxy for non-professional investors. Typically, master's students in business possess basic accounting knowledge and are familiar with investing (Libby et al. 2002, p. 803), which is sufficient for the goal of our experiment. Although this is a common practice in experimental accounting and auditing research (e.g., Cheng et al. 2015, p. 141; Libby et al. 2002), the sample used did not fully represent all characteristics of the general population of non-professional investors (see Cheng et al. 2015, p. 156). We should also keep in mind that sustainability reports are often designed to reach a broader set of stakeholders (e.g., employees, customers). We did not explicitly test for other groups of readers. Therefore, our results are generalizable to other reader groups in a limited way. However, it would be interesting to test our experiment with professional subjects with a higher level of exposure to sustainability disclosure and experience in sustainability assurance. Second, we presented an extract of the sustainability report to participants. The stimulus contained two environmental and two social sustainability topics and a shortened assurance report (see the Appendix 2).
In practice, sustainability reports are considerably longer and cover a variety of different topics. While our stimulus is based on a fictitious company in the textile industry, literature shows industry differences in the exposure to sustainability risks and in the adoption of sustainability assurance (Casey and Grenier 2015; Kolk and Perego 2010; Pflugrath et al. 2011; Simnett et al. 2009). Typically, sustainability reports entail a higher degree of complexity than the extract presented in our experiment. Due to the mix of quantitative and qualitative information or the integration of text, tables, and other visual elements (e.g., Cho et al. 2012; Hellmann et al. 2017; Merkl-Davies and Brennan 2007), it is more difficult for readers to filter and interpret the relevant information. When generalizing our results, readers should keep in mind that participants may react differently to more extensive and more complex reports. Third, we concentrated on sustainability reports in the format of a separately published sustainability report. In practice, we also observe a growing number of integrated reports. Typically, financial information is externally assured, while oftentimes only parts of the non-financial information have been subject to assurance. This creates an even more complex scenario for sustainability report readers. Therefore, it is likely that the confusion between assured and non-assured information increases further (Hodge 2001; IDW 2018), which could influence sustainability report readers' credibility perceptions. Although we expect that assurance depth and reference explicitness have a similar effect on credibility perceptions, our results are only conditionally transferable to the scenario of integrated reporting. Fourth, our study examines only two choices of assurance reports, reference explicitness and assurance depth. In our experimental design, we did not manipulate other managerial choices concerning the assurance statement.

The limitations presented offer opportunities for further research. Such research could investigate additional sustainability assurance choices, such as different levels of the assurance, changes in the applied methods, or the wording of the assurance statement (Hummel et al. 2019, p. 736). Additionally, the assessment of materiality could be varied. An experimental setting could analyze different degrees of coverage or a mix of material and non-material topics. Furthermore, there are promising avenues for further research in investigating the use of different graphical references to mark sustainability assurance. For example, future research can focus on different symbols, their size and color, or combinations of visual and verbal information. An experimental 
approach under the utilization of eye-tracking equipment could be adopted for such purposes. This technology enables a richer analysis of the reader's judgment-making process. This approach also offers opportunities to further investigate signal interpretation processes. An empirical study examining recent assurance reports could analyze the use of graphical references for different levels of assurance. Such an approach would further complement the study by Gürtürk and Hahn (2016) that was based on a sample of published sustainability reports for 2012 .

Further research could also investigate the motivations of firms when assigning assurance. Such research could investigate how companies strategically decide the different elements of assurance, for example, by comparing the motives of management to choose different assurance options with the credibility perceptions of readers. Studying the motives and goals of organizations could provide deeper insights into false signaling and potential impression management. In particular, this stage of the assurance engagement raises further questions of managerial capture and ethical conduct.

Funding Open Access funding enabled and organized by Projekt DEAL. This study was funded by the Bavarian Research Alliance (BayFOR grant number BayIntAn_KUEI_2019_07).

\section{Compliance with Ethical Standards}

Conflict of interest The authors declare that they have no conflict of interest.

Ethical Approval All procedures performed in studies involving human participants were in accordance with the ethical standards of the Macquarie University Human Research Ethics Committee.

Informed Consent Informed consent was obtained from all individual participants included in the study.

Open Access This article is licensed under a Creative Commons Attribution 4.0 International License, which permits use, sharing, adaptation, distribution and reproduction in any medium or format, as long as you give appropriate credit to the original author(s) and the source, provide a link to the Creative Commons licence, and indicate if changes were made. The images or other third party material in this article are included in the article's Creative Commons licence, unless indicated otherwise in a credit line to the material. If material is not included in the article's Creative Commons licence and your intended use is not permitted by statutory regulation or exceeds the permitted use, you will need to obtain permission directly from the copyright holder. To view a copy of this licence, visit http://creativecommons.org/licenses/by/4.0/.

\section{Appendix 1: Background and Materiality Assessment}

\section{Background}

The fictitious company $\mathrm{ABC}$ is a multinational corporation that is engaged in the design, development, manufacturing, and worldwide marketing and sales of footwear, clothing, and accessories. ABC and its associated companies operate in 58 countries with over 3500 stores and as of 2017 employed around 116,000 people. It is the third-largest global clothing retailer. The company has a significant online presence, with online shopping available in 32 countries.

\section{Materiality Assessment}

It is very important for $\mathrm{ABC}$ and its stakeholders (e.g., customers, investors, employees, suppliers etc.) that the company respects the environment by reducing emissions. Furthermore, as a representative of the textile industry, stakeholders attach value to the protection of human rights.

Therefore, the two most important topics for $\mathrm{ABC}$ are:

- Emissions

- Human rights

On the next screen, you will see an excerpt from ABC's current sustainability report, written in accordance with the sustainability reporting standards of the Global Reporting Initiative (GRI).

\section{Appendix 2: Excerpt of ABC's Sustainability Report for Treatment 1}

Treatment 1 refers to high assurance depth and high reference explicitness. 
The following is an excerpt from ABC's sustainability report:

\section{Environmental data}

Biodiversity

ABC's Overall Biodiversity Score includes indicators based on reporting on biodiversity at operational sites, significant impacts on biodiversity, and habitats protected or restored.

ABC's Overall Biodiversity Score is out of 100; 100 is best. Individual measures are out of 7; 7 is best.

Overall Biodiversity Score

$\mathrm{ABC}$

Industry average

\begin{tabular}{ll} 
Individual measures & Score \\
\hline Biodiversity at operational sites & $\ldots \ldots \ldots$ \\
Significant impacts on biodiversity & $\ldots \ldots \ldots$ \\
Habitats protected or restored & $\ldots \ldots \ldots$
\end{tabular}

Habitats protected or restored

$\cdots \cdots \cdots$
Emissions

ABC's Overall Emissions Score includes indicators based on reporting on direct (Scope 1), indirect (Scope 2), and reduction of greenhouse gas (GHG) emissions.

ABC's Overall Emissions Score is out of 100; 100 is best. Individual measures are out of 7; 7 is best.

Overall Emissions Score

$\mathrm{ABC}$

Industry average

Individual measures

Direct (Scope 1) emissions $\quad \ldots \ldots$.

Indirect (Scope 2) emissions $\quad \ldots \ldots \ldots$

Reduction of GHG emissions $\quad \ldots \ldots \ldots$

\section{Social data}

Human rights $\checkmark$

ABC's Overall Human Rights Score includes indicators based on reporting on child and forced labor, security practices, and human rights assessment.

ABC's Overall Human Rights Score is out of 100; 100 is best. Individual measures are out of 7; 7 is best.

\begin{tabular}{ll} 
Overall Human Rights Score \\
\hline $\mathrm{ABC}$ & 87 \\
Industry average & 57
\end{tabular}

\begin{tabular}{ll} 
Individual measures & Score \\
\hline Child and forced labor & $\ldots \ldots \ldots$ \\
Security practices & $\ldots \ldots \ldots$
\end{tabular}

Human rights assessment $\quad \ldots \ldots$.

\section{Diversity and equal opportunity}

ABC's Overall Diversity and Equal Opportunity Score includes indicators based on reporting on diversity of employees, diversity of governance bodies, and salary and remuneration differences between women and men.

ABC's Overall Diversity and Equal Opportunity Score is out of 100; 100 is best. Individual measures are out of 7; 7 is best.

Overall Diversity and Equal Opportunity Score

$\mathrm{ABC}$

Industry average

\begin{tabular}{ll} 
Individual measures & Score \\
\hline Diversity of employees & $\ldots \ldots \ldots$ \\
Diversity of governance bodies & $\ldots \ldots \ldots$ \\
Ratio of basic salary and & $\ldots \ldots \ldots$
\end{tabular}

remuneration of women to men 


\section{Independent Assurance Report}

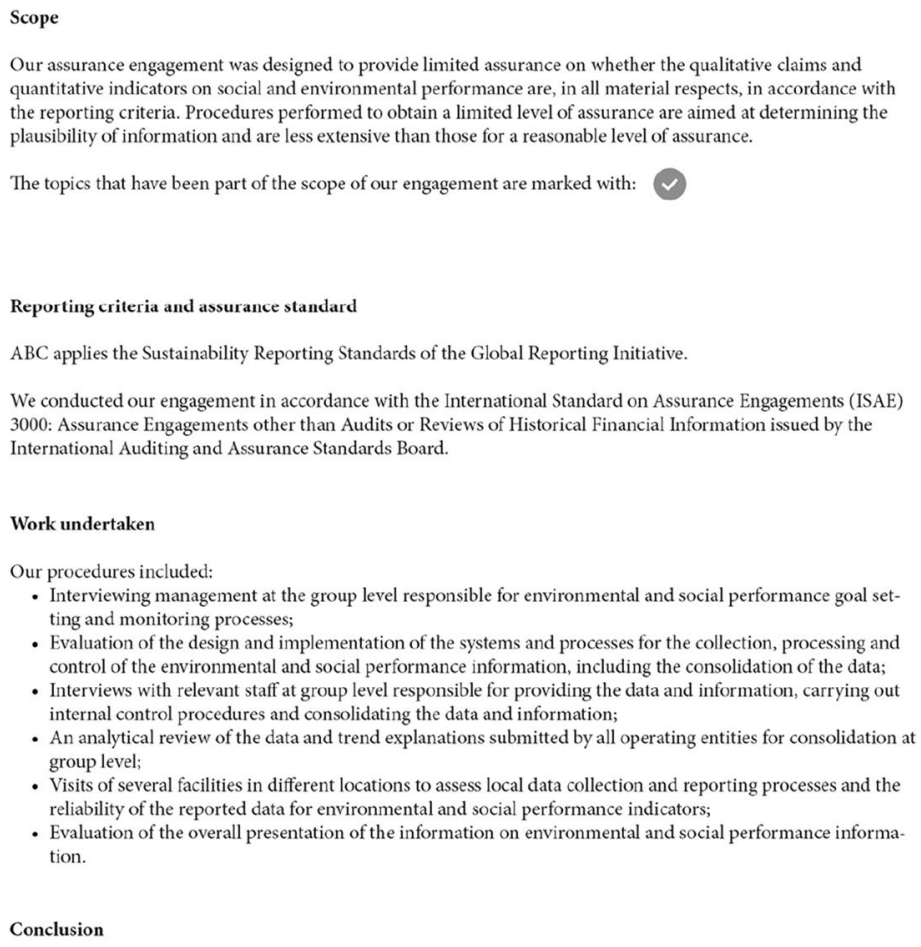

- Visits of several facilities in different locations to assess local data collection and reporting processes and the reliability of the reported data for environmental and social performance indicators;

- Evaluation of the overall presentation of the information on environmental and social performance information.

Conclusion

Based on the procedures performed, as described above, nothing has come to our attention to indicate that the environmental and social performance information for the business year 2017 are not presented in accordance with the reporting criteria.

August 2, 2018

XYZ Assurance Company

\section{References}

AA. (2018). AA1000 accountability principles. London: AccountAbility.

Allianz. (2016). Allianz sustainability report 2015. Munich.

Alon, A., \& Vidovic, M. (2015). Sustainability performance and assurance: Influence on reputation. Corporate Reputation Review, $18(4), 337-352$.

Ang, L., Hellmann, A., Kanbaty, M., \& Sood, S. (2020). Emotional and attentional influences of photographs on impression management and financial decision making. Journal of Behavioral and Experimental Finance, 27, 100348.

Bagnoli, M., \& Watts, S. G. (2017). Voluntary assurance of voluntary CSR disclosure. Journal of Economics and Management Strategy, 26(1), 205-230.

Ball, A., Owen, D. L., \& Gray, R. (2000). External transparency or internal capture? The role of third-party statements in adding value to corporate environmental reports. Business Strategy and the Environment, 9(1), 1-23.

Boiral, O., Heras-Saizarbitoria, I., Brotherton, M.-C., \& Bernard, J. (2019). Ethical issues in the assurance of sustainability reports: Perspectives from assurance providers. Journal of Business Ethics, 159(4), 1111-1125.

Branzei, O., Ursacki-Bryant, T. J., Vertinsky, I., \& Zhang, W. (2004). The formation of green strategies in Chinese firms: Matching corporate environmental responses and individual principles. Strategic Management Journal, 25(11), 1075-1095.

Callery, P. J., \& Perkins, J. (2020). Detecting false accounts in intermediated voluntary disclosure. Academy of Management Discoveries. https://doi.org/10.5465/amd.2018.0229.

Canning, M., O’Dwyer, B., \& Georgakopoulos, G. (2019). Processes of auditability in sustainability assurance-The case of materiality construction. Accounting and Business Research, 49(1), 1-27.

Casey, R. J., \& Grenier, J. H. (2015). Understanding and contributing to the enigma of corporate social responsibility (CSR) assurance in the United States. Auditing, 34(1), 97-130.

Certo, S. T. (2003). Influencing initial public offering investors with prestige: Signaling with board structures. Academy of Management Review, 28(3), 432-446.

Cheng, M. M., Green, W. J., \& Chi Wa Ko, J. (2015). The impact of strategic relevance and assurance of sustainability indicators on investors' decisions. Auditing: A Journal of Practice \& Theory, 34(1), 131-162.

Childers, T. L., \& Houston, M. J. (1984). Conditions for a picturesuperiority effect on consumer memory. Journal of Consumer Research, 11(2), 643.

Cho, C. H., Laine, M., Roberts, R. W., \& Rodrigue, M. (2015). Organized hypocrisy, organizational façades, and sustainability reporting. Accounting, Organizations and Society, 40, 78-94. 
Cho, C. H., Michelon, G., \& Patten, D. M. (2012). Enhancement and obfuscation through the use of graphs in sustainability reports. Sustainability Accounting, Management and Policy Journal, 3(1), 74-88.

Cho, C. H., Michelon, G., Patten, D. M., \& Roberts, R. W. (2014). CSR report assurance in the USA: An empirical investigation of determinants and effects. Sustainability Accounting, Management and Policy Journal, 5(2), 130-148.

Cho, S. Y., Lee, C., \& Pfeiffer, R. J. (2013). Corporate social responsibility performance and information asymmetry. Journal of Accounting \& Public Policy, 32(1), 71-83.

Clarkson, P., Li, Y., Richardson, G., \& Tsang, A. (2019). Causes and consequences of voluntary assurance of CSR reports. Accounting, Auditing \& Accountability Journal, 32(8), 2451-2474.

Cohen, J., Holder-Webb, L., Nath, L., \& Wood, D. (2011). Retail investors' perceptions of the decision-usefulness of economic performance, governance, and corporate social responsibility disclosures. Behavioral Research in Accounting, 23(1), 109-129.

Cohen, J. R., \& Simnett, R. (2015). CSR and assurance services: A research agenda. Auditing: A Journal of Practice \& Theory, 34(1), 59-74.

Connelly, B. L., Certo, S. T., Ireland, R. D., \& Reutzel, C. R. (2011). Signaling theory: A review and assessment. Journal of Management, 37(1), 39-67.

Cooper, S., \& Owen, D. (2014). Independent assurance of sustainability reports. In J. Bebbington, J. Unerman, \& B. O’Dwyer (Eds.), Sustainability accounting and accountability (2nd ed., pp. 72-85). New York: Routledge.

Coram, P. J., Monroe, G. S., \& Woodliff, D. R. (2009). The value of assurance on voluntary nonfinancial disclosure: An experimental evaluation. Auditing, 28(1), 137-151.

Dando, N., \& Swift, T. (2003). Transparency and assurance: Minding the credibility gap. Journal of Business Ethics, 44(2), 195-200.

Datar, S. M., Feltham, G. A., \& Hughes, J. S. (1991). The role of audits and audit quality in valuing new issues. Journal of Accounting and Economics, 14(1), 3-49.

David, P. (1998). News concreteness and visual-verbal association do news pictures narrow the recall gap between concrete and abstract news? Human Communication Research, 25(2), 180-201.

Djamasbi, S., Siegel, M., \& Tullis, T. (2011). Visual hierarchy and viewing behavior: An eye tracking study. Human-Computer Interaction. Design and Development Approaches, 6761(1), 331-340

Ehrhart, K. H., \& Ziegert, J. C. (2005). Why are individuals attracted to organizations? Journal of Management, 31(6), 901-919.

Elliott, W. B., Hodge, F. D., Kennedy, J. J., \& Pronk, M. (2007). Are MBA students a good proxy for nonprofessional investors? The Accounting Review, 82(1), 139-168.

Fonseca, A. (2010). How credible are mining corporations' sustainability reports? A critical analysis of external assurance under the requirements of the international council on mining and metals. Corporate Social Responsibility and Environmental Management, 17(6), 355-370.

Fuhrmann, S., Ott, C., Looks, E., \& Guenther, T. W. (2017). The contents of assurance statements for sustainability reports and information asymmetry. Accounting and Business Research, 47(4), 369-400.

G\&A. (2014). Sustainability-What matters? New York: Governance \& Accountability Institute Inc.

Gammoh, B. S., Voss, K. E., \& Chakraborty, G. (2006). Consumer evaluation of brand alliance signals. Psychology and Marketing, 23(6), 465-486.

Gao, H., Darroch, J., Mather, D., \& MacGregor, A. (2008). Signaling corporate strategy in IPO communication: A study of biotechnology IPOs on the NASDAQ. Journal of Business Communication, 45(1), 3-30.

Gray, R. (2000). Current developments and trends in social and environmental auditing, reporting and attestation: A review and comment. International Journal of Auditing, 4(3), 247-268.

GRI (2013). Sustainability topics for sectors: What do stakeholders want to know? Amsterdam: Global Reporting Initiative.

GRI. (2018). Consolidated set of sustainability reporting standards. Amsterdam: Global Sustainability Standards Board and Global Reporting Initiative.

GRI, CSR Europe, \& Accountancy Europe. (2017). Member state implementation of directive 2014/95/EU: A comprehensive overview of how member states are implementing the EU directive on non-financial and diversity information. CSR Europe and Global Reporting Initiative.

Gürtürk, A., \& Hahn, R. (2016). An empirical assessment of assurance statements in sustainability reports: Smoke screens or enlightening information? Journal of Cleaner Production, 136, $30-41$.

Habermas, J. (1984). The theory of communicative action. Boston: Beacon Press.

Hahn, R., \& Kühnen, M. (2013). Determinants of sustainability reporting: A review of results, trends, theory, and opportunities in an expanding field of research. Journal of Cleaner Production, 59, $5-21$.

Hahn, R., \& Lülfs, R. (2014). Legitimizing negative aspects in GRIoriented sustainability reporting: A qualitative analysis of corporate disclosure strategies. Journal of Business Ethics, 123(3), 401-420.

Hahn, R., \& Reimsbach, D. (2020). Bringing signaling theory to intermediated voluntary disclosure. Commentary on "Detecting False Accounts in Intermediated Voluntary Disclosure" by Patrick Callery and Jessica Perkins. Academy of Management Discoveries. https://doi.org/10.5465/amd.2020.0015.

Hahn, R., Reimsbach, D., Kotzian, P., Feder, M., \& Weißenberger, B. E. (2019). Legitimation strategies as valuable signals in nonfinancial reporting? Effects on investor decision-making. Business \& Society. https://doi.org/10.1177/0007650319872495.

Hasan, M., Maijoor, S., Mock, T. J., Roebuck, P., Simnett, R., \& Vanstraelen, A. (2005). The different types of assurance services and levels of assurance provided. International Journal of Auditing, 9(2), 91-102.

Hasan, M., Roebuck, P. J., \& Simnett, R. (2003). An investigation of alternative report formats for communicating moderate levels of assurance. Auditing: A Journal of Practice \& Theory, 22(2), 171-187.

Healy, P., \& Palepu, K. (2001). Information asymmetry, corporate disclosure, and the capital markets: A review of the empirical disclosure literature. Journal of Accounting and Economics, 31(1-3), 405-440.

Hellmann, A., Yeow, C., \& De Mello, L. (2017). The influence of textual presentation order and graphical presentation on the judgements of non-professional investors. Accounting and Business Research, 47(4), 455-470.

Highhouse, S., Thornbury, E. E., \& Little, I. S. (2007). Social-identity functions of attraction to organizations. Organizational Behavior and Human Decision Processes, 103(1), 134-146.

Hodge, F. D. (2001). Hyperlinking unaudited information to audited financial statements: Effects on investor judgments. The Accounting Review, 76(4), 675-691.

Hodge, K., Subramaniam, N., \& Stewart, J. (2009). Assurance of sustainability reports: Impact on report users' confidence and perceptions of information credibility. Australian Accounting Review, 19(3), 178-194. 
Holder-Webb, L., Cohen, J. R., Nath, L., \& Wood, D. (2009). The supply of corporate social responsibility disclosures among U.S. firms. Journal of Business Ethics, 84(4), 497-527.

Hooghiemstra, R. (2000). Corporate communication and impression management-New perspectives why companies engage in corporate social reporting. Journal of Business Ethics, 27(1/2), $55-68$.

Hummel, K., Schlick, C., \& Fifka, M. (2019). The role of sustainability performance and accounting assurors in sustainability assurance engagements. Journal of Business Ethics, 154(3), 733-757.

IDW (2018). Trendwatch-Externes Reporting_IDW Positionspapier zu Bestandteilen der externen Berichterstattung und zur Reichweite ihre Prüfung. Düsseldorf: Institut der Wirtschaftsprüfer in Deutschland e.V. (Institute of Public Auditors in Germany).

Jarvenpaa, S. L. (1990). Graphic displays in decision making-The visual salience effect. Journal of Behavioral Decision Making, 3(4), 247-262.

Jensen, M. C., \& Meckling, W. H. (1976). Theory of the firm: Managerial behavior, agency costs and ownership structure. Journal of Financial Economics, 3(4), 305-360.

Kanbaty, M., Hellmann, A., \& He, L. (2020). Infographics in corporate sustainability reports: Providing useful information or used for impression management? Journal of Behavioral and Experimental Finance, 26, 100309.

Kaplan, S., Kaplan, R., \& Sampson, J. R. (1968). Encoding and arousal factors in free recall of verbal and visual material. Psychonomic Science, 12(2), 73-74.

Kausar, A., Shroff, N., \& White, H. (2016). Real effects of the audit choice. Journal of Accounting and Economics, 62(1), 157-181.

Köksal, D., Strähle, J., Müller, M., \& Freise, M. (2017). Social sustainable supply chain management in the textile and apparel industry-A literature review. Sustainability, 9(1), 100.

Kolk, A., \& Perego, P. (2010). Determinants of the adoption of sustainability assurance statements: An international investigation. Business Strategy \& the Environment, 19(3), 182-198.

KPMG. (2017). The road ahead-The KPMG survey of corporate responsibility reporting 2017. KPMG International Cooperative.

Kuruppu, S., \& Milne, M. J. (2010). Dolphin deaths, organizational legitimacy and potential employees' reactions to assured environmental disclosures. Accounting Forum, 34(1), 1-19.

Libby, R., Bloomfield, R. J., \& Nelson, M. W. (2002). Experimental research in financial accounting. Accounting, Organizations and Society, 27(8), 775-810.

Lock, I., \& Seele, P. (2017). Measuring credibility perceptions in CSR communication: A scale development to test readers' perceived credibility of CSR reports. Management Communication Quarterly, 31(4), 584-613.

Lougee, B., \& Wallace, J. (2008). The corporate social responsibility (CSR) trend. Journal of Applied Corporate Finance, 20(1), 96-108

Lurie, N. H., \& Mason, C. H. (2007). Visual representation: Implications for decision making. Journal of Marketing, 71(1), $160-177$.

Lutz, K. A., \& Lutz, R. J. (1978). Imagery-eliciting strategies: Review and implications of research. Advances in Consumer Research, 5, 611-620.

Lyon, T. P., \& Maxwell, J. W. (2011). Greenwash: Corporate environmental disclosure under threat of audit. Journal of Economics \& Management Strategy, 20(1), 3-41.

Lys, T., Naughton, J. P., \& Wang, C. (2015). Signaling through corporate accountability reporting. Journal of Accounting and Economics, 60(1), 56-72.

Maines, L. A., \& McDaniel, L. S. (2000). Effects of comprehensiveincome characteristics on nonprofessional investors' judgments: The role of financial-statement presentation format. The Accounting Review, 75(2), 179-207.
Manetti, G., \& Becatti, L. (2009). Assurance services for sustainability reports: Standards and empirical evidence. Journal of Business Ethics, 87(1), 289-298.

Maroun, W. (2020). A conceptual model for understanding corporate social responsibility assurance practice. Journal of Business Ethics, 161, 187-209.

Martínez-Ferrero, J., \& García-Sánchez, I.-M. (2018). The level of sustainability assurance: The effects of brand reputation and industry specialisation of assurance providers. Journal of Business Ethics, 150(4), 971-990.

Mercer, M. (2004). How do investors assess the credibility of management disclosures? Accounting Horizons, 18(3), 185-196.

Merkl-Davies, D. M., \& Brennan, N. M. (2007). Discretionary disclosure strategies in corporate narratives: Incremental information or impression management? Journal of Accounting Literature, 26, 116-194.

Michelon, G., Pilonato, S., \& Ricceri, F. (2015). CSR reporting practices and the quality of disclosure: An empirical analysis. Critical Perspectives on Accounting, 33, 59-78.

Mock, T. J., Rao, S. S., \& Srivastava, R. P. (2013). The development of worldwide sustainability reporting assurance. Australian Accounting Review, 23(4), 280-294.

Mock, T. J., Stohm, C., \& Swartz, K. M. (2007). An examination of worldwide assured sustainability reporting. Australian Accounting Review, 17(41), 67-77.

Morris, S. A. (1997). Internal effects of stakeholder management devices. Journal of Business Ethics, 16(4), 413-424.

Neu, D. (1991). Trust, impression management and the public accounting profession. Critical Perspectives on Accounting, 2(3), 295-313.

Neu, D., Warsame, H., \& Pedwell, K. (1998). Managing public impressions: Environmental disclosures in annual reports. Accounting, Organizations and Society, 23(3), 265-282.

O'Dwyer, B. (2003). Conceptions of corporate social responsibility: The nature of managerial capture. Accounting, Auditing \& Accountability Journal, 16(4), 523-557.

O'Dwyer, B. (2011). The case of sustainability assurance: Constructing a new assurance service. Contemporary Accounting Research, 28(4), 1230-1266.

O'Dwyer, B., \& Owen, D. L. (2005). Assurance statement practice in environmental, social and sustainability reporting: a critical evaluation. The British Accounting Review, 37(2), 205-229.

Oelze, N. (2017). Sustainable supply chain management implementation-Enablers and barriers in the textile industry. Sustainability, 9(8), 1435.

Owen, D. L., Swift, T. A., Humphrey, C., \& Bowerman, M. (2000). The new social audits: Accountability, managerial capture or the agenda of social champions? European Accounting Review, 9(1), $81-98$.

Paivio, A. (1969). Mental imagery in associative learning and memory. Psychological Review, 76(3), 241-263.

Paivio, A., Rogers, T. B., \& Smythe, P. C. (1968). Why are pictures easier to recall than words? Psychonomic Science, 11(4), 137-138.

Parke, C. (2015). Essential first steps to data analysis: Scenario-based examples using SPSS. Thousand Oaks: SAGE Publications Inc.

Perego, P. (2009). Causes and consequences of choosing different assurance providers: An international study of sustainability reporting. International Journal of Management, 26(3), 412-425.

Perego, P., \& Kolk, A. (2012). Multinationals' accountability on sustainability: The evolution of third-party assurance of sustainability reports. Journal of Business Ethics, 110(2), 173-190.

Perkins, S. J., \& Hendry, C. (2005). Ordering top pay: Interpreting the signals. Journal of Management Studies, 42(7), 1443-1468.

Pflugrath, G., Roebuck, P., \& Simnett, R. (2011). Impact of assurance and assurer's professional affiliation on financial analysts' 
assessment of credibility of corporate social responsibility information. Auditing, 30(3), 239-254.

Ramaswami, A., Dreher, G. F., Bretz, R., \& Wiethoff, C. (2010). Gender, mentoring, and career success: The importance of organizational context. Personnel Psychology, 63(2), 385-405.

Reimsbach, D., \& Hahn, R. (2015). The effects of negative incidents in sustainability reporting on investors' judgments-an experimental study of third-party versus self-disclosure in the realm of sustainable development. Business Strategy and the Environment, 24(4), 217-235.

Reimsbach, D., Hahn, R., \& Gürtürk, A. (2018). Integrated reporting and assurance of sustainability information: An experimental study on professional investors' information processing. European Accounting Review, 27(3), 559-581.

Reimsbach, D., Schiemann, F., Hahn, R., \& Schmiedchen, E. (2020). In the eyes of the beholder: Experimental evidence on the contested nature of materiality in sustainability reporting. Organization \& Environment, 33(4), 624-651.

Rousseeuw, P. J., \& Hubert, M. (2011). Robust statistics for outlier detection. Wiley Interdisciplinary Reviews: Data Mining and Knowledge Discovery, 1(1), 73-79.

Sampson, J. R. (1970). Free recall of verbal and non-verbal stimuli. Quarterly Journal of Experimental Psychology, 22(2), 215-221.

SASB. (2015). Apparel, accessories \& footwear. Research Brief. San Francisco: Sustainability Accounting Standards Board.

Shen, H., Wu, H., \& Chand, P. (2017). The impact of corporate social responsibility assurance on investor decisions: Chinese evidence. International Journal of Auditing, 21(3), 271-287.

Simnett, R., Vanstraelen, A., \& Chua, W. F. (2009). Assurance on sustainability reports: An international comparison. The Accounting Review, 84(3), 937-967.

Smith, J., Haniffa, R., \& Fairbrass, J. (2011). A conceptual framework for investigating 'capture' in corporate sustainability reporting assurance. Journal of Business Ethics, 99(3), 425-439.

Spence, M. (1973). Job market signaling. Quarterly Journal of Economics, 87(3), 355-374.

Spence, M. (2002). Signaling in retrospect and the informational structure of markets. American Economic Review, 92(3), 434-459.

Srivastava, J. (2001). The role of inferences in sequential bargaining with one-sided incomplete information: Some experimental evidence. Organizational Behavior and Human Decision Processes, 85(1), 166-187.
Stiglitz, J. E. (2000). The contributions of the economics of information to twentieth century economics. The Quarterly Journal of Economics, 115(4), 1441-1478.

Suazo, M. M., Martínez, P. G., \& Sandoval, R. (2009). Creating psychological and legal contracts through human resource practices: A signaling theory perspective. Human Resource Management Review, 19(2), 154-166.

Sundar, A., \& Kellaris, J. J. (2017). How logo colors influence shoppers' judgments of retailer ethicality: The mediating role of perceived eco-friendliness. Journal of Business Ethics, 146(3), 685-701.

Taufique, K., Siwar, C., Talib, B., Sarah, F., \& Chamhuri, N. (2014). Synthesis of constructs for modeling consumers' understanding and perception of eco-labels. Sustainability, 6(4), 2176-2200.

Thomas, E. B. (1983). Visual superiority effect in memory (pictures are worth a thousand words). Proceedings of the Human Factors Society Annual Meeting, 27(8), 714-714.

Tukey, J. W. (1977). Exploratoty data analysis. Reading: AddisonWesley Publishing.

Turban, D. B., \& Greening, D. W. (1997). Corporate social performance and organizational attractiveness to prospective employees. Academy of Management Journal, 40(3), 658-672.

Verrecchia, R. E. (1983). Discretionary disclosure. Journal of Accounting and Economics, 5, 179-194.

Watson, A., Shrives, P., \& Marston, C. (2002). Voluntary disclosure of accounting ratios in the UK. The British Accounting Review, 34(4), 289-313.

Zerbini, F. (2017). CSR initiatives as market signals: A review and research agenda. Journal of Business Ethics, 146(1), 1-23.

Zhou, S., Simnett, R., \& Green, W. J. (2016). Assuring a new market: The interplay between country-level and company-level factors on the demand for greenhouse gas (GHG) information assurance and the choice of assurance provider. Auditing: A Journal of Practice \& Theory, 35(3), 141-168.

Publisher's Note Springer Nature remains neutral with regard to jurisdictional claims in published maps and institutional affiliations. 